\title{
What is the respiratory retention of inhaled hexamethylene di-isocyanate?
}

\author{
E. Monso*, Y. Cloutier ${ }^{\#}$, J. Lesage ${ }^{\#}$, G. Perreault", J-L. Malo*
}

\begin{abstract}
What is the respiratory retention of inhaled hexamethylene di-isocyanate? E. Monso, $Y$. Cloutier, J. Lesage, G. Perreault, J-L. Malo. CERS Journals Ltd 2000.

ABSTRACT: Isocyanates are a frequent cause of occupational asthma. Specific inhalation challenges are often required to confirm the diagnosis. The inhaled concentration has to be assessed during this procedure. However, the respiratory retention of di-isocyanate has not, to the authors knowledge, been evaluated in humans.

The existence of a closed-circuit apparatus, designed to carry out these challenges, makes it possible to assess the dose. The respiratory retention of hexamethylene diisocyanate (HDI) generated in vapour form, in both normal subjects $(n=4)$ and subjects referred for the investigation of occupational asthma due to HDI in whom the diagnosis was excluded $(n=5)$, was assessed. The latter group included four subjects with nonoccupational asthma.

The HDI was generated at concentrations varying 5.1-15.2 ppb. The expired concentrations of HDI during such challenges varied 1.4-5.3 ppb. Therefore, the respiratory retention was $61-90 \%$.

To conclude, the majority of inhaled hexamethylene di-isocyanate vapour is retained within the airways and/on lung parenchyma.

Eur Respir J 2000; 16: 729-730.
\end{abstract}

*Dept of Chest Medicine, Hôpital du Sacré-Coeur, Montreal, Canada. " The Institut de recherche en santé et sécurité du travail du Québec, Montreal, Canada.

\section{Correspondence: J-L. Malo}

Dept of Chest Medicine

Sacré-Coeur Hospital

5400 West Gouin Blvd

Montreal

Canada H4J $1 \mathrm{C} 5$

Fax: 5143383123

Keywords: Inhalation challenges isocyanates

occupational asthma

Received: June 131999

Accepted after revision May 292000
Isocyanates are a common cause of occupational asthma (OA) [1]. Specific inhalation challenges with the causal agent are used to confirm the diagnosis in specialized centres [2]. For these tests, the inhaled concentration has to remain stable and below the threshold-limit-value (TLV) for a short-term exposure, that is $<20 \mathrm{ppb}$ in the case of hexamethylene di-isocyanate (HDI) [3]. However, the key factor that determines an asthmatic reaction is more likely to be the respiratory retention than the concentration. As far as we know, the proportion of inhaled HDI that is retained has not been determined.

Therefore, an assessment was carried out of the dose of inhaled HDI using an apparatus that has been described previously [2]. This apparatus allows on-line information to be obtained about the inhaled and exhaled concentrations, thus enabling the respiratory retention to be assessed.

\section{Material and methods}

The apparatus used for inhalation challenge procedures with HDI has been described [2]. Briefly, it includes three components: a generator of isocyanates, an exposure chamber and instruments for on-line assessment of concentration. The subject inhales isocyanate vapours at spontaneous tidal volume breathing through a mouthpiece connected to the central part of a plexiglass cylinder covered with Teflon, which is, in effect, the exposure chamber. Isocyanate concentrations were assessed with a GMD instrument (model 720-120; GMD Systems Inc., Pittsburgh, PA, USA) by connecting the port to the inhalation tube. The total length of the 2-cm-diameter tube, connecting the 9 exposure chamber to the mouth, was $26 \mathrm{~cm}$. The inspiratory port was located at a distance of $12 \mathrm{~cm}$ from the subject's mouth while the expiratory port was $2 \mathrm{~cm}$ away from the mouth. Use of unidirectional valves $(n=4)$ avoided contamination of the inspired and expired air samples. Assessments of concentrations were carried out in three phases: 1) The stability of the inspiratory concentrations was monitored; 2) expiratory concentration was assessed; and 3) the inspiratory concentration was measured again to ensure it was comparable to the concentration during the first phase of assessment. The GMD instrument assesses the concentration for variable durations of sampling. If the concentration is $<10 \mathrm{ppb}$ (as was the case for the expiratory measures), the assessment cycle lasts for $4 \mathrm{~min}$. However, 1-min measurements are extrapolated from the 4-min readings. The duration of assessment (inspiration and expiration) lasted for $4 \mathrm{~min}$ or more in all instances. Readings obtained with this instrument had previously been compared with results obtained by liquid chromatography, and were shown to be accurate (unpublished) data.

Nine subjects were exposed to HDI vapour using a methodology previously described [2]. This includes four normal volunteers who were nonsmokers and had no respiratory conditions, and five nonsmoking subjects referred for the investigation of occupational asthma and in whom a previous or concomitant investigation excluded this diagnosis. Four of these subjects suffered from nonoccupational asthma (baseline forced expiratory volume in one second (FEV1) varying $61-112 \%$ pred [4], 
Table 1. - Concentrations of hexamethylene di-isocyanate (HDI) in the inspired and expired air with derivation of respiratory retention

\begin{tabular}{lccc}
\hline & \multicolumn{2}{c}{ Concentration } & $\begin{array}{c}\text { Respiratory } \\
\text { retention* \% }\end{array}$ \\
\cline { 2 - 3 } \multicolumn{2}{c}{ Inspired air } & Expired air & \\
\cline { 2 - 3 } Normal subjects & & \\
1 & $13.2 \pm 0.3(\mathrm{n}=7)$ & $1.6 \pm 0.4(\mathrm{n}=12)$ & 88 \\
2 & $11.1 \pm 0.7(\mathrm{n}=12)$ & $3.8 \pm 0.5(\mathrm{n}=10)$ & 66 \\
3 & $5.1 \pm 0.7(\mathrm{n}=12)$ & $1.6 \pm 0.3(\mathrm{n}=13)$ & 69 \\
4 & $15.2 \pm 1.1(\mathrm{n}=15)$ & $4.5 \pm 0.1(\mathrm{n}=4)$ & 70 \\
Subjects investigated for & possible occupational asthma** \\
5 & $12.9 \pm 0.6(\mathrm{n}=10)$ & $2.0 \pm 0.4(\mathrm{n}=12)$ & 84 \\
6 & $10.2 \pm 1.6(\mathrm{n}=10)$ & $2.4 \pm 1.5(\mathrm{n}=5)$ & 76 \\
7 & $13.2 \pm 0.5(\mathrm{n}=4)$ & $4.3 \pm 2.0(\mathrm{n}=26)$ & 67 \\
8 & $14.0 \pm 1.0(\mathrm{n}=6)$ & $1.4 \pm 0.1(\mathrm{n}=5)$ & 90 \\
9 & $13.7 \pm 1.8(\mathrm{n}=10)$ & $5.3 \pm 0.3(\mathrm{n}=11)$ & 61 \\
\hline
\end{tabular}

Data presented as mean \pm SD values with number of assessments (mean value for $2 \mathrm{~min}$ ). *: (mean concentration of the inspired air - mean concentration of the expired air)/mean concentration of the inspired air $\times 100$; **: all but one subject had common asthma.

provocative concentration of methacholine causing a 20\% fall in FEV1 (PC20) using a standardized methodology [5] varying $\left.0.1-8 \mathrm{mg} \cdot \mathrm{mL}^{-1}\right)$. All subjects gave their consent for participating in the study and the project was accepted by the hospital ethics committee.

\section{Results}

Table 1 summarizes the results. The inspired concentrations of HDI varied from $5.1 \pm 0.7$ to a maximum of $15.2 \pm 1.1$ parts per billion (ppb). The stability of generation was satisfactory, as shown by relatively small SD values. The expired air concentrations varied from a minimum value of $1.4 \pm 0.1-5.3 \pm 0.3 \mathrm{ppb}$. The percentage of HDI vapour that remained within the airways, therefore, was $61-90 \%$ and was of the same order of magnitude for the normal and asthmatic subjects.

\section{Discussion}

This report shows that a high proportion of inhaled HDI generated as a vapour is retained within the airways. This high level of retention can reasonably be explained by the high water content of the airways, since isocyanates are hydrophilic and can thus, readily be absorbed within the aqueous milieu of the airway lining fluid [6]. Overall, the behaviour of HDI vapour seems to be similar to the general behaviour of volatile organic solvents.

It is indeed generally accepted that $60-70 \%$ of volatile organic solvents are absorbed on inhalation in sedentary individuals, leaving $30-40 \%$ exhaled in the breath [7].

The site of retention within the airways is unknown. In particular, the proportion of the inhaled dose that reaches the bronchi, which is relevant to the asthmatic reaction, remains speculative. Indeed, a proportion of isocyanates probably remains in the upper airways. Tracking the HDI with an isotope would obviously be interesting. It is not excluded that a proportion of HDI was absorbed by the plastic material of the tubing. As mentioned in the method section, $14 \mathrm{~cm}$ separated the exposure chamber from the inspiratory port. The mean inspiratory concentrations differed by $2-3 \mathrm{ppb}$ from the concentrations assessed in the exposure chamber, which suggests some absorption in the plastic tubing. Therefore, it is likely that in the part of the tubing that separates the inspiratory port from the mouth (an equivalent distance to that separating the inspiratory port and the mouth), there could be an equivalent absorption as well (2-3 ppb). This, however, is much lower than the difference observed between the inspiratory and expiratory ports.

When di-isocyanates react with water, the corresponding diamines can theoretically be generated. Since the GMD monitor used only assessed isocyanates and not amines, it is conceivable that the amount of nondeposited HDI was underestimated, if HDI vapour had reacted with water vapour in the airway lumen before being deposited. However, whereas amines may be generated when diisocyanates are mixed with water in liquid form, to the best of the authors' knowledge, amines are not detected when di-isocyanates are mixed with water vapour, which is the case for humidified air in the airways unpublished data). It is, therefore, believed that the concentration of HDI in the expired air did not significantly underestimate the amount of nonabsorbed HDI.

The TLV for short-term-exposure of HDI vapour has been set at a concentration $<20 \mathrm{ppb}$ [3]. Because the majority of inhaled HDI remains within the airways, it is important to respect this threshold.

To conclude, the respiratory retention of inhaled hexamethylene di-isocyanate generated as a vapour is $>50 \%$.

\footnotetext{
Acknowledgements. The authors want to thank L. Schubert for reviewing this manuscript.
}

\section{References}

1. Vandenplas O, Malo JL, Saetta M, Mapp CE, Fabbri L. Occupational asthma and extrinsic alveolitis due to isocyanates: current status and perspectives. $\mathrm{Br} J$ Ind Med 1993; 50: 213-228.

2. Vandenplas O, Malo JL. Inhalation challenges with agents causing occupational asthma. Eur Respir J 1997; 10: 2612-2629.

3. American Governmental Industrial Hygienists Conference. 1998 TLVs and BEls. Threshold Limit Values for Chemical Substances and Physical Agents. Cincinnati, OH, 1998.

4. Knudson RJ, Lebowitz MD, Holberg CJ, Burrows B. Changes in the normal maximal expiratory flow-volume curve with growth and aging. Am Rev Respir Dis 1983; 127: 725-734.

5. Cockcroft DW, Killian DN, Mellon JJA, Hargreave FE. Bronchial reactivity to inhaled histamine: a method and clinical survey. Clin Aller 1977; 7: 235-243.

6. Woods G. The ICI Polyurethanes Book 2nd ed. Chichester, ICI Polyurethanes and John Wiley \& Sons, 1990.

7. Lee SQ. Biological monitoring. An introduction. Van Nostrand Reinhold, New York, 1993; p. 148. 